\title{
Journal of Vasculitis: A Forum for Vasculitis Researchers from East to West, from Bench to Clinic
}

\author{
Chien-Sheng $\mathbf{W u}^{1,2^{*}}$ \\ ${ }^{1}$ Department of Internal Medicine, Far Eastern Memorial Hospital, Taiwan \\ ${ }^{2}$ Department of Internal Medicine, National Taiwan University Hospital, Taiwan
}

*Corresponding author: Chien-Sheng Wu, Department of Internal Medicine, Far Eastern Memorial Hospital, No.21, Sec.2, Nan-Ya South Road, Banciao Dist., New Taipei City 220, Taiwan, Tel: +886 277282148; Fax: +886 223570212; E-mail: wucs@mail.femh.org.tw

Received date: November 04, 2015, Accepted date: November 10, 2015, Published date: November 17, 2015

Copyright: (c) 2015 Wu CS. This is an open-access article distributed under the terms of the Creative Commons Attribution License, which permits unrestricted use, distribution, and reproduction in any medium, provided the original author and source are credited.

\section{Introduction}

Is vasculitis research important? Do we need an open access journal for vasculitis? The answers to both questions are yes, vasculitis research is important and we need an open access journal for vasculitis and only vasculitis. But why and how?

The vasculitides represent a wide range of diseases, from vasculitis involving skin only to systemic large vessel arteritis without any superficial signs [1]. This group of diseases are highly diverse and some are rare with an annual incidence between $1 / 10,000$ to $1 / 1,000,000$. This disease term may arouse fear in not only patients but also general practicing physicians. Some vasculitis such as Henoch-Schonlein purpura is relatively common and self-limited; while some vasculitis like anti-neutrophil antibody associated vasculitis (AAV) is rare but associated with severe consequences. In clinical practice, vasculitis can be difficult to be diagnosed. For example, patients with granulomatosis with polyangiitis (GPA) can present with sinus, lung, kidney or nervous system involvements. Due to the diversity and highly variable responses to treatment of some vasculitis, the learning curve progress slowly.

The clinical diagnosis of vasculitis relies on a constellation of clinical manifestations, serologic markers and pathology study. The sensitivity and specificity of classification/diagnosis criteria can be influenced by local disease incidence and prevalence. To understand the economic burden of disease, epidemiology study can provide some valuable insights. However, the distribution map of vasculitides is largely unfilled. One of the famous examples that shows the importance of epidemiology studies is the Sily Road disease-Behcet's disease, which distributes mainly from Turkey to Japan, implies the impact of population migration or even a transmissible pathogen; we need more evidence to confirm these disease spread model [2]. Giant cell arteritis (GCA) is another remarkable example because it is the most prevalent vasculitis in northern Europe but the incidence of GCA in Asia is estimated in only limited studies [3-5]. When I was a trainee of rheumatology, I expected to find a few new cases of GCA according to the incidence documented in textbook but finally I witnessed only one atypical young patient throughout the entire training course [6]. Later I was surprised to find that GCA is even more rare than GPA in Taiwan. Therefore we need international studies to prove some hypotheses about disease distribution and differentiate the ethnic/ genetic impact on the incidence of vasculitis [7]. Traditional epidemiology study in a relatively closed area is a reliable method for defining the incidence and prevalence of vasculitides [8]. For study of common or rare vasculitis such as Henoch-Schonlein purpura or GPA, national health insurance data in some countries can provide an estimation $[9,10]$.
For researchers of rare diseases, patient recruitment is difficult. For clinical trials, the rare diseases as study targets tend to be neglected due to limited economic return of new medication investigation. In recent days, multiple-center study group organized for clinical trials such as RAVE-ITN Research Group and EUVAS have generated many excellent results [11,12]. However, there are still unmet needs in clinical practice and research. For example, disease activity index such as the Birmingham vasculitis activity score (BVAS) is validated in clinical researches [13], but it is difficult to be used in daily practice. A good biomarker is easier to be checked and followed in clinical setting. In addition, good animal models of vasculitis are also required for the study of pathogenesis and development of new therapy. These issues should be prioritized and may bring about some breakthrough in vascular physiology and even change the landscape of treatment of other common disease such as cerebrovascular disease or coronary heart diseases.

Why is an open access journal for vasculitis the answer to these challenges? According to PubMed (accessed on Oct 29, 2015), using vasculitis as a key word generated 2579 results in 2014, while lupus as a key word generated 2830 results. This simple query results show that vasculitides as a group is gaining importance compared to lupus, which is a well-recognized central issue in immune-mediated diseases. A good open access journal can provide a forum for relative specialized group of vasculitis researchers to be heard by researchers across different specialties. An active and dedicating editorial board can define the field of vasculitis research by selecting influential articles and provide new points of view to hasten the development of research. Open access journals are increasing in number and competition is not less intensive than prescription oriented classic journals, therefore interaction between editors and authors as well as review and publication quality control will be the keys to success.

Let's say happy birthday to the open access Journal of Vasculitis, hope this journal can become a corner stone of future vasculitis researches.

\section{References}

1. Jennette JC, Falk RJ, Bacon PA, Basu N, Cid MC, et al. (2013) 2012 revised International Chapel Hill Consensus Conference Nomenclature of Vasculitides. Arthritis Rheum 65: 1-11.

2. Piga M, Mathieu A (2014) The origin of Behçet's disease geoepidemiology: possible role of a dual microbial-driven genetic selection. Clin Exp Rheumatol 32: S123-129.

3. Pereira LS, Yoon MK, Hwang TN, Hong JE, Ray K, et al. (2011) Giant cell arteritis in Asians: a comparative study. Br J Ophthalmol 95: 214-216. 
Citation: Wu CS (2015) Journal of Vasculitis: A Forum for Vasculitis Researchers from East to West, from Bench to Clinic. J Vasc 1: e105. doi: $10.4172 / 2471-9544.1000 \mathrm{e} 105$

Page 2 of 2

4. Kobayashi S, Yano T, Matsumoto Y, Numano F, Nakajima N, et al. (2003) Clinical and epidemiologic analysis of giant cell (temporal) arteritis from a nationwide survey in 1998 in Japan: the first government-supported nationwide survey. Arthritis Rheum 49: 594-598.

5. Tam S and Wong TC (2008) Temporal arteritis in hong kong. Inter J Rheu Dis 11: 163-169.

6. Wu CS, Hsu KL, Chang YL, Lee KL (2004) Giant cell arteritis with CD8+ instead of CD4+ T lymphocytes as the predominant infiltrating cells in a young woman. J Microbiol Immunol Infect 37: 246-249.

7. Fujimoto S, Watts RA, Kobayashi S, Suzuki K, Jayne DR, et al. (2011) Comparison of the epidemiology of anti-neutrophil cytoplasmic antibodyassociated vasculitis between Japan and the U.K. Rheumatology (Oxford) 50: 1916-1920.

8. Gonzalez-Gay MA, Garcia-Porrua C, Guerrero J, Rodriguez-Ledo P and Llorca J (2003) The epidemiology of the primary systemic vasculitides in northwest spain: Implications of the chapel hill consensus conference definitions. Arthritis Rheum 49: 388-393.
9. Yang YH, Hung CF, Hsu CR, Wang LC, Chuang YH, et al. (2005) A nationwide survey on epidemiological characteristics of childhood Henoch-Schönlein purpura in Taiwan. Rheumatology (Oxford) 44: 618-622.

10. Wu CS, Hsieh CJ2, Peng YS3, Chang TH3, Wu ZY4 (2015) Antineutrophil cytoplasmic antibody-associated vasculitis in Taiwan: A hospital-based study with reference to the population-based National Health Insurance database. J Microbiol Immunol Infect 48: 477-482.

11. Stone JH, Merkel PA, Spiera R, Seo P, Langford CA, et al. (2010) Rituximab versus cyclophosphamide for ANCA-associated vasculitis. N Engl J Med 363: 221-232.

12. Jones RB, Tervaert JW, Hauser T, Luqmani R, Morgan MD, et al. (2010) Rituximab versus cyclophosphamide in ANCA-associated renal vasculitis. N Engl J Med 363: 211-220.

13. Luqmani RA, Bacon PA, Moots RJ, Janssen BA, Pall A, et al. (1994) Birmingham Vasculitis Activity Score (BVAS) in systemic necrotizing vasculitis. QJM 87: 671-678. 